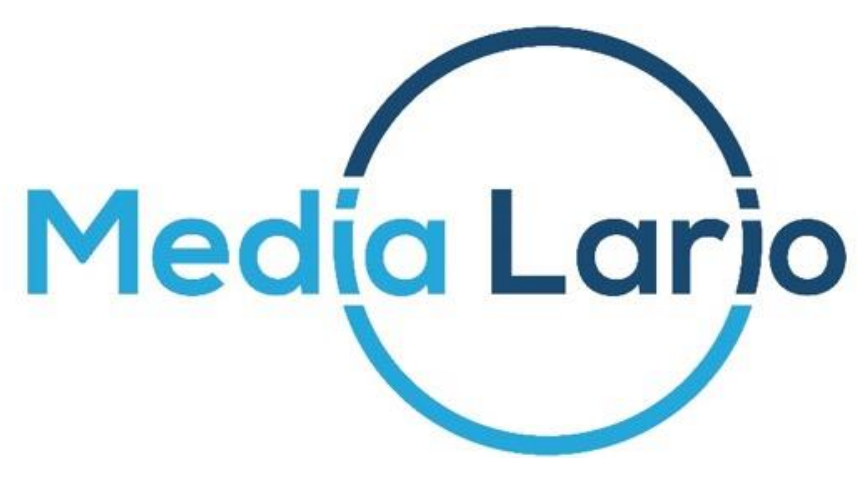

High Precision Optics and Optical Systems

\title{
ATHENA Telescope: alignment and integration of SPO Mirror Modules
}

Giuseppe Valsecchi

10 October, 2018

ICSO 2018: Telescope Integration

Paper Number 43 


\section{Outline}

- Concept of optical alignment of the ATHENA mirror modules

- Media Lario experiences and expertise in X-ray optics

- Optical bench and Handling and Alignment Device

- Tests with mirror modules and optical demonstration

- UV and X-ray performance verification and results

- Conclusions

- Next step: facility for ATHENA flight telescope 


\section{Concept for integration of ATHENA optics}

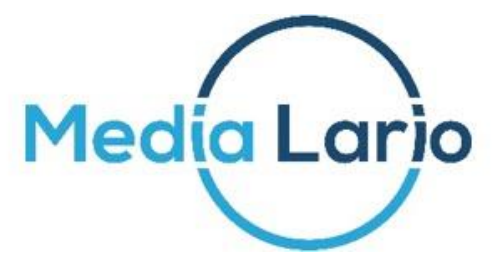

- The alignment and integration concept is based on the UV imaging at $218 \mathrm{~nm}$ of each mirror module on the $12 \mathrm{~m}$ focal plane

- The position of the centroid of the point spread function (PSF) produced by each mirror module when illuminated by a collimated plane wave is used as reference for the precise alignment of the mirror module

- The diffraction induced by the SPO channels is not a limiting factor

- A 6 axis semi-automatic manipulator aligns the Mirror Module and place it on top of three pins

- The bonding process freezes the mirror module in position 


\section{UV vertical optical bench for integration of ATHENA}

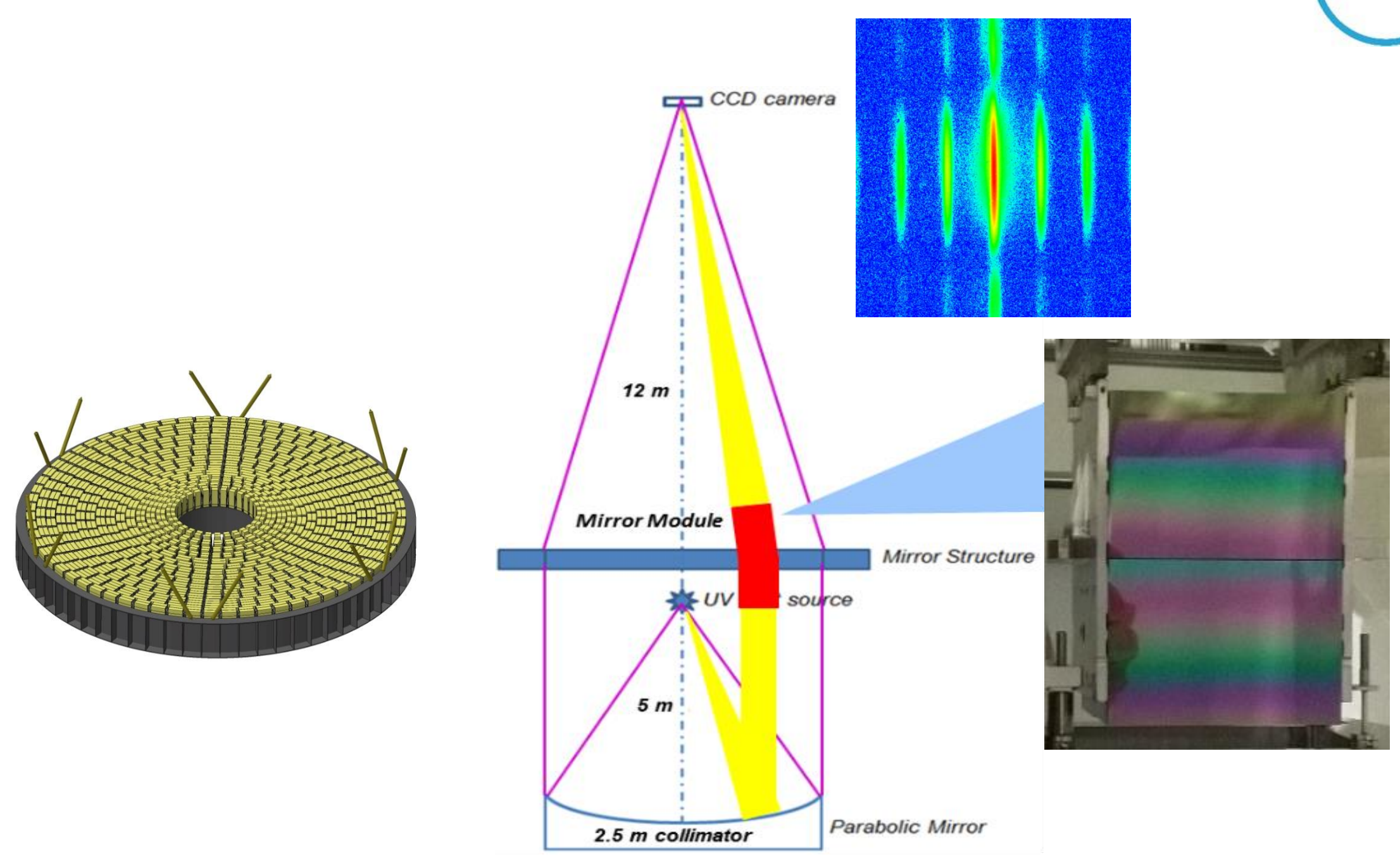

$218 \mathrm{~nm}$ focal plane images enable accurate SPO MM integration 


\section{ATHENA MM Optical Alignment Procedure}
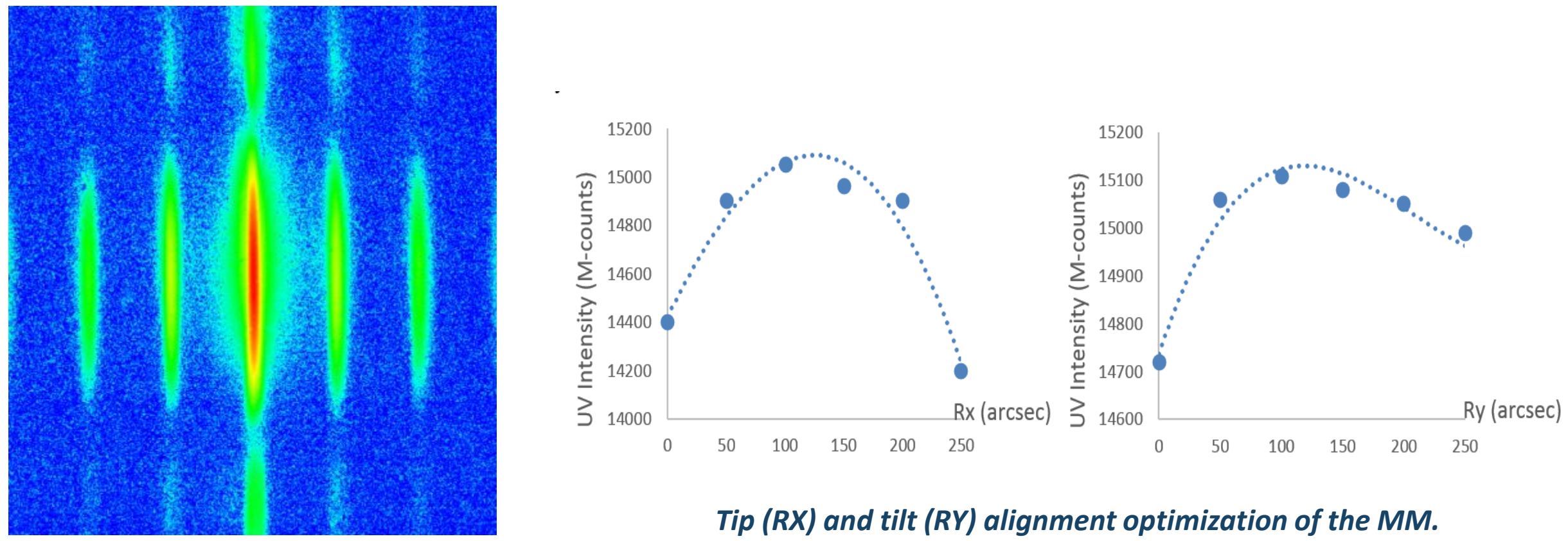

UV focal plane image of MM

Tip $(R X)$ and tilt $(R Y)$ alignment optimization of the MM.

- $\mathrm{RX}, \mathrm{RY}$ alignment achieved from the maximization of photon count

- $\Delta \mathrm{X}, \Delta \mathrm{Y}, \mathrm{RZ}$ alignment achieved by centering the centroid

- $\Delta \mathrm{Z}$ from mechanical reference (loose tolerance)

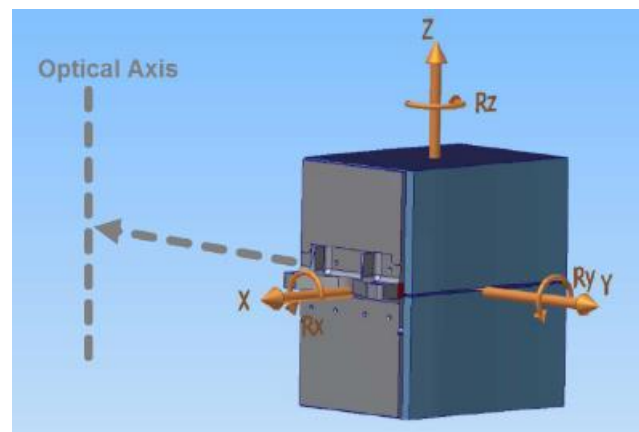




\section{5-year Heritage in X-ray Optics Alignment}

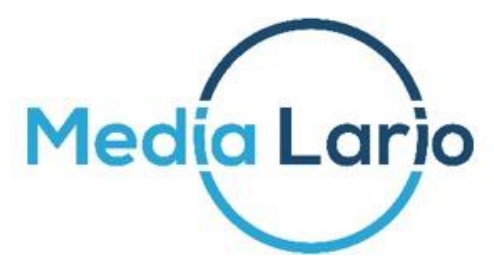

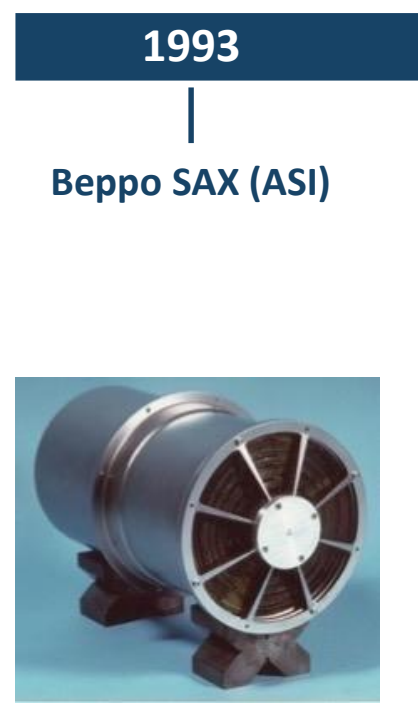

- 4 mirror modules

- 30 mirrors/module

- Thickness: 0.4-2 mm

- HEW: $60^{\prime \prime}$

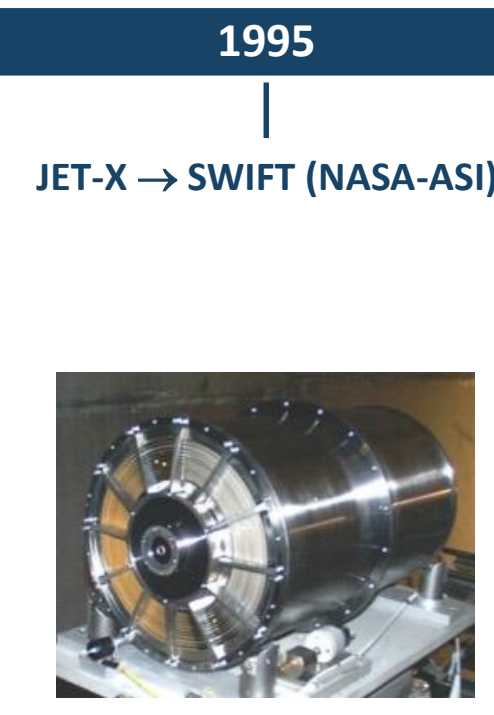

- 3 mirror modules

- 12 mirrors/module

- Thickness: 0.4-1.5 mm

- HEW: 15"
1999

XMM NEWTON (ESA)

The most powerful $X$-ray

telescope ever built

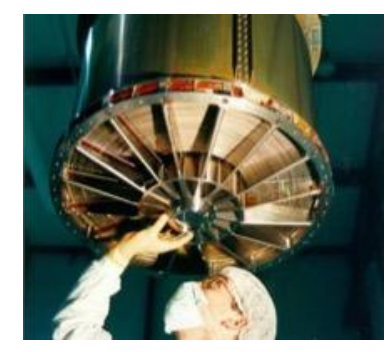

- 4 mirror modules

- 58 mirrors/module

- Thickness: 0.5-1 mm

- HEW: 13"

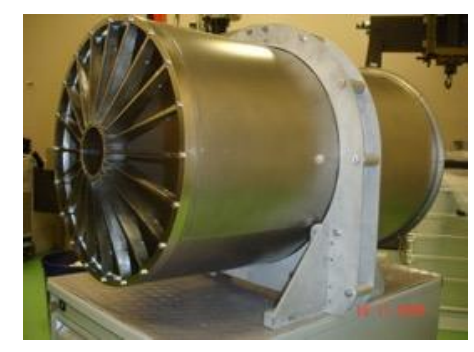

- New mandrel technology

- Aperiodic multilayer for

hard- $X$ ray reflection

\section{3}

NHXM technology

development (ASI)

EROSITA (MPE)

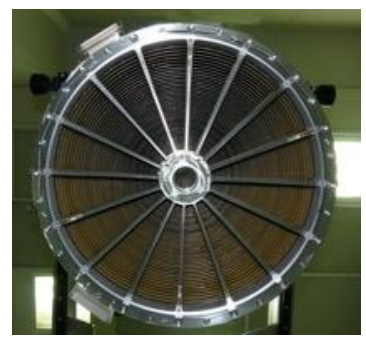

- 8 mirror modules

- 54 mirrors/module

- Thickness: 0.2-0.5 mm

- HEW: $14 "$

\section{Developing next $X$-ray astronomy missions:}

Einstein Probe (ESA-CAS, China), ARCUS (NASA), and ATHENA (ESA) 


\section{ATHENA MM Alignment Error Budget}

\begin{tabular}{|c|c|c|c|c|}
\hline $\begin{array}{l}\text { HEW telescope } \\
\text { error budget }\end{array}$ & $\begin{array}{l}\text { Requirements } \\
\text { [arcsec] }\end{array}$ & $\begin{array}{l}\text { Goal } \\
\text { [arcsec] }\end{array}$ & & \\
\hline Mirror Module & 4.3 & 2.5 & & \\
\hline $\begin{array}{l}\text { Alignment and } \\
\text { integration }\end{array}$ & (1.5) & (1.0) & $\sigma_{\text {centroids }} \leq \frac{1}{1.349} \sqrt{H E W_{\text {Population }}^{2}-H E W_{M M}^{2}}$ & $0.74 \operatorname{arcsec}$ \\
\hline Distortions & 1.5 & 1.0 & 1 & \\
\hline $\begin{array}{l}\text { Spacecraft } \\
\text { related }\end{array}$ & 1.0 & 0.5 & $\sigma_{\text {centroids }} \leq \overline{1.349} \sqrt{H E W_{\text {Population }}^{2}-H E W_{M M}^{2}}=$ & 1.11 arcsec \\
\hline Margin & 1.0 & 0.5 & & \\
\hline RSS & 5.0 & 3.0 & & \\
\hline
\end{tabular}

The MM alignment error budget was derived from the overall telescope error budget 


\section{Sub-system AIT error budget for ATHENA telescope}

\begin{tabular}{|c|c|c|}
\hline Sub System & Parameter & Budget for ATHENA telescope \\
\hline \multirow[t]{2}{*}{ Telescope integration } & HEW & $<1.5$ arcsec \\
\hline & Effective area loss & $<1 \%$ \\
\hline \multirow[t]{2}{*}{ MM accuracy } & Accuracy of MM focal length & $<1.5 \div 2.5 \mathrm{~mm}$ \\
\hline & $\mathrm{X} / \mathrm{Y}$ alignment accuracy of brackets & $<0.5 \mathrm{~mm}$ \\
\hline \multirow[t]{3}{*}{ MM alignment } & Max X/Y errors & $<12 \mu \mathrm{m}$ \\
\hline & Max RX error & $<10 \div 30$ arcsec \\
\hline & Max RY error & $<30 \div 120$ arcsec \\
\hline \multirow[t]{7}{*}{ VOB } & Collimation of UV illumination beam & $>95 \mathrm{~km}$ \\
\hline & Collimation stability & $>1500$ km \\
\hline & Z position accuracy of the source & $<380 \mu \mathrm{m}$ \\
\hline & Z position stability of the source & $<23 \mu \mathrm{m}$ \\
\hline & Z position accuracy of the CCD camera & $<1.5 \mathrm{~mm}$ \\
\hline & Z position stability of the CCD camera & $<93 \mu \mathrm{m}$ \\
\hline & RZ stability during curing & $<1.5 \div 9 \operatorname{arcsec}$ \\
\hline
\end{tabular}




\section{Handling and Alignment Device (HAD)}

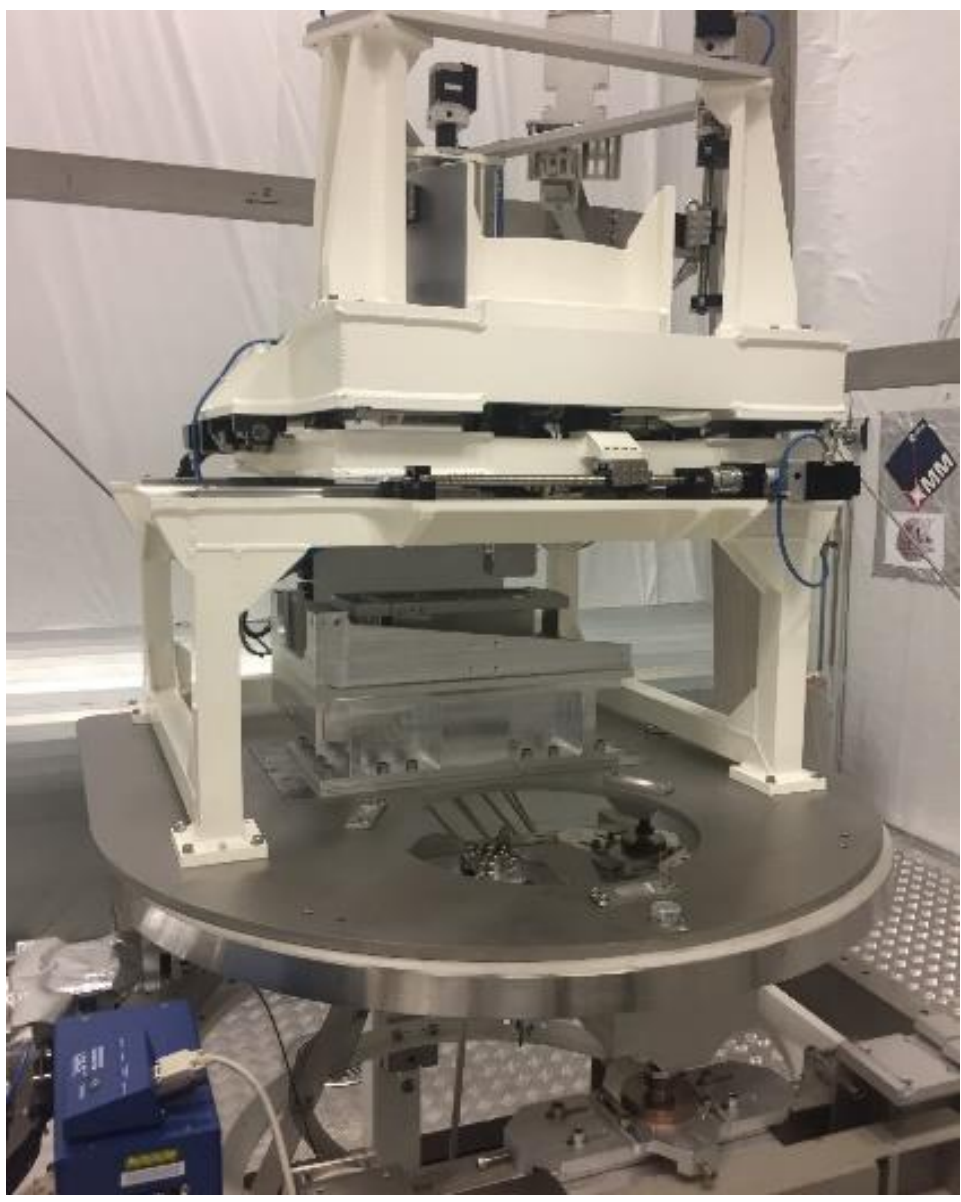

\begin{tabular}{|l|c|c|}
\hline Positioning & Range & Adjustment step \\
\hline $\mathrm{X}$ translation & $\pm 100 \mathrm{~mm}$ & $\pm 0.5 \mu \mathrm{m}$ \\
\hline $\mathrm{Y}$ translation & $-25 \div+90 \mathrm{~mm}$ & $\pm 0.5 \mu \mathrm{m}$ \\
\hline$Z$ translation & $120 \mathrm{~mm}$ & $\pm 0.5 \mu \mathrm{m}$ \\
\hline $\mathrm{X}$ rotation & $\pm 2^{\circ}$ & $\pm 2 \operatorname{arcsec}$ \\
\hline $\mathrm{Y}$ rotation & $\pm 2^{\circ}$ & $\pm 2 \operatorname{arcsec}$ \\
\hline$Z$ rotation & $360^{\circ}$ & $\pm 0.5 \operatorname{arcsec}$ \\
\hline
\end{tabular}

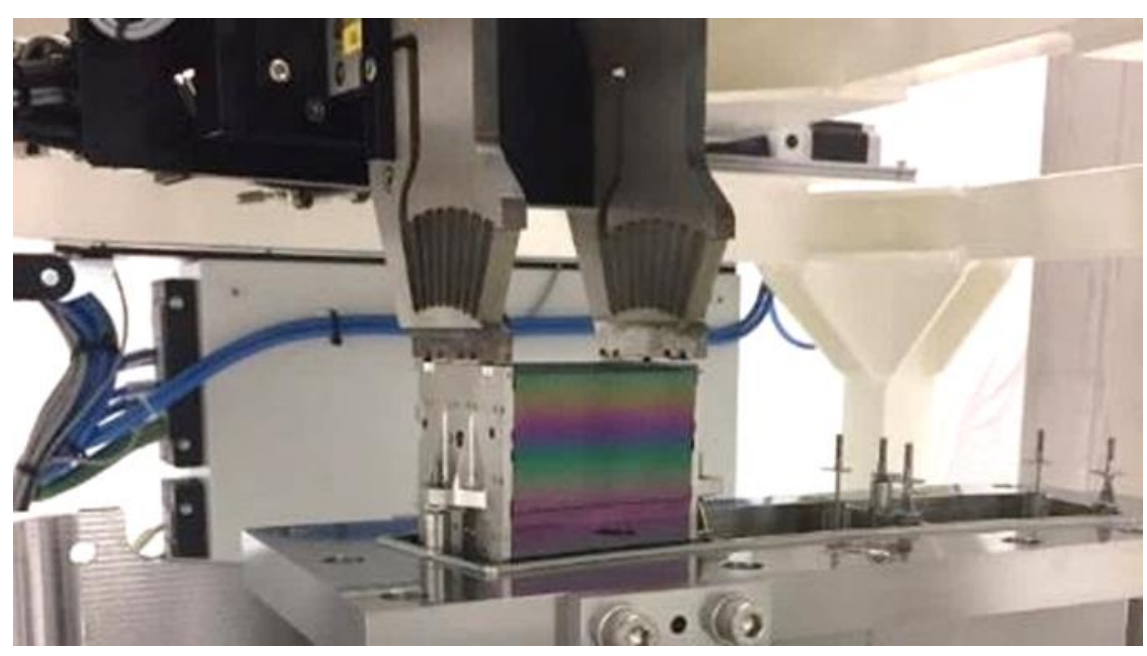

HAD is designed for semi-automatic loading, positioning, and alignment of the mirror modules HAD allows moving the mirror modules in all six degrees of freedom 


\section{ATHENA Integration Demonstrator}

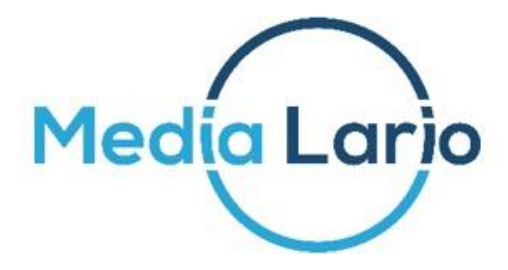

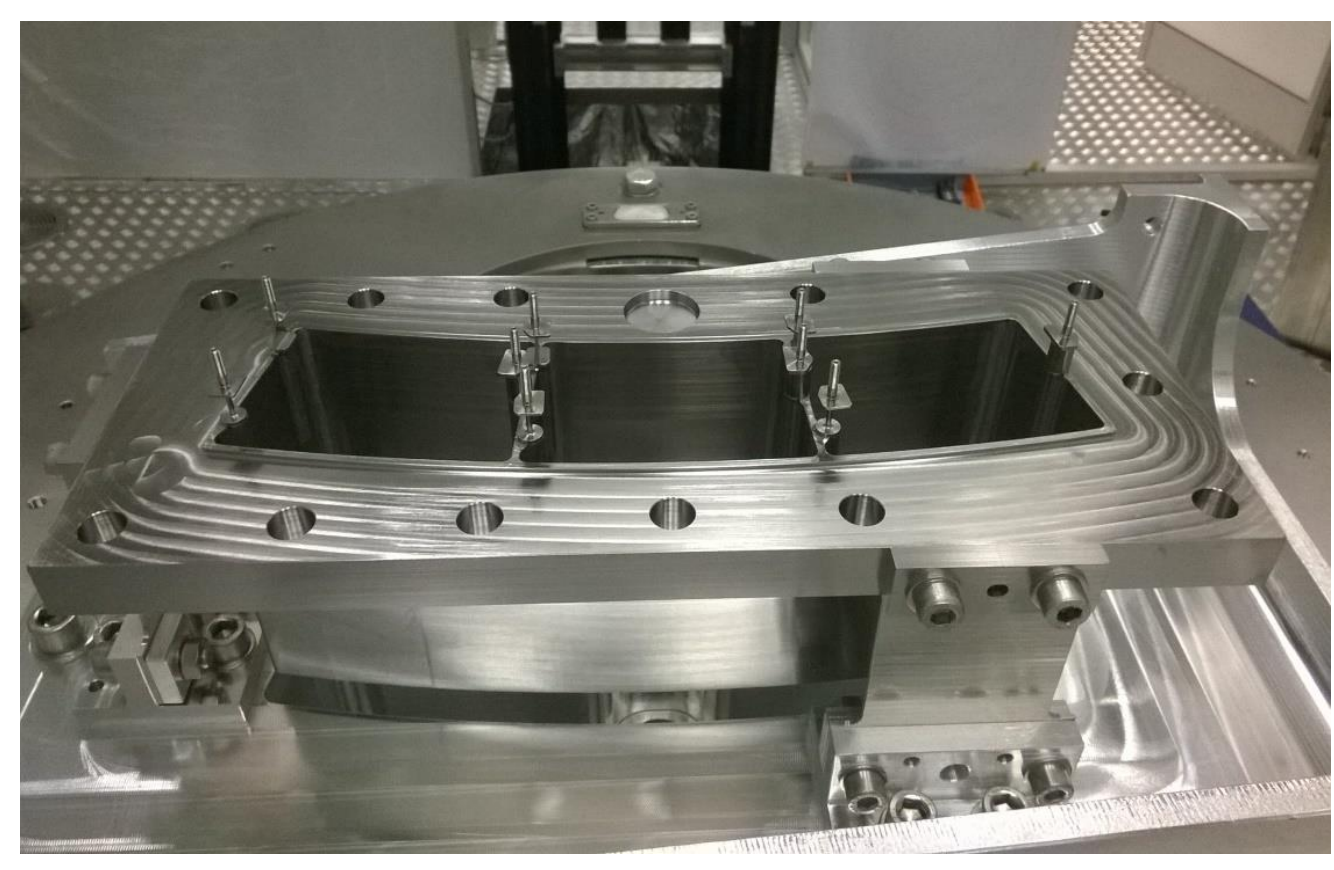

Titanium Mirror Structure Element for 3 MM's

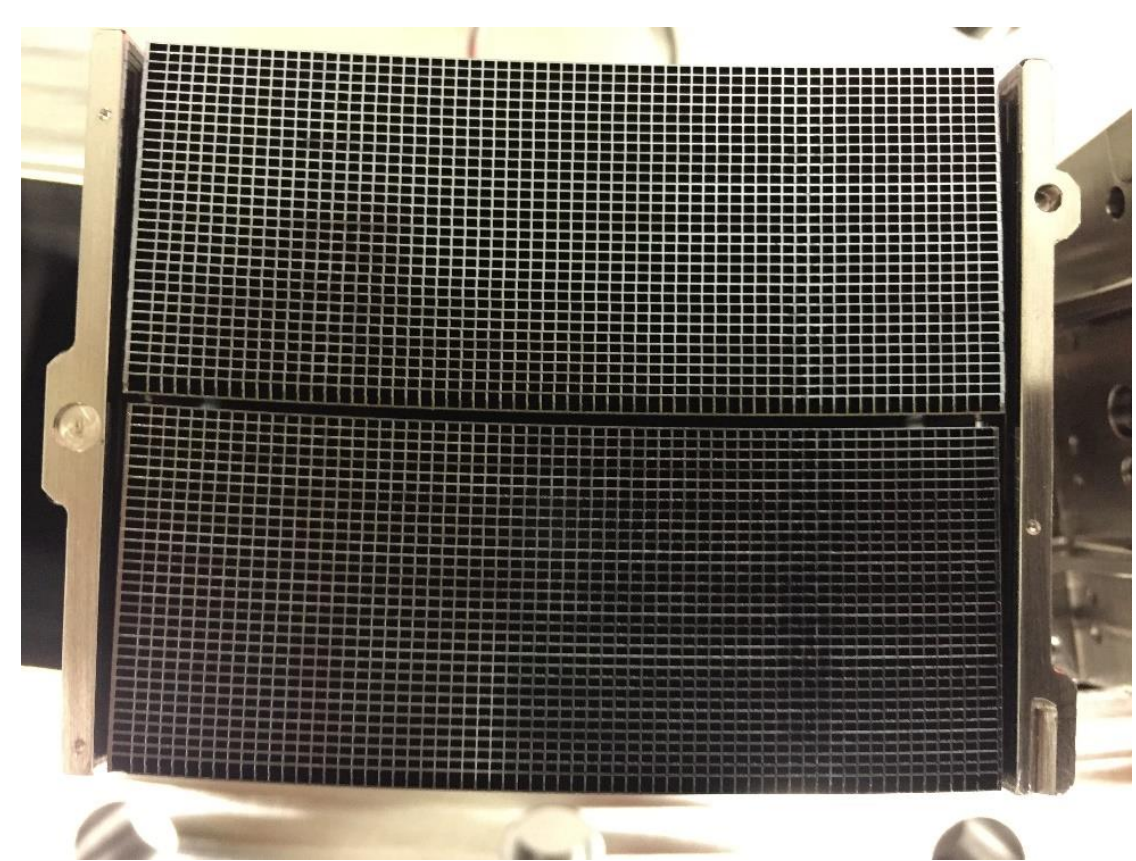

SPO MM provided by Cosine

- Representative cut-out of the ATHENA mirror structure with room for 3 MM's

- Dowel pins are first glued in the structure

- 2 SPO MM's provided by Cosine, \#0025 and \#0027 


\section{ATHENA Integration Demonstrator}
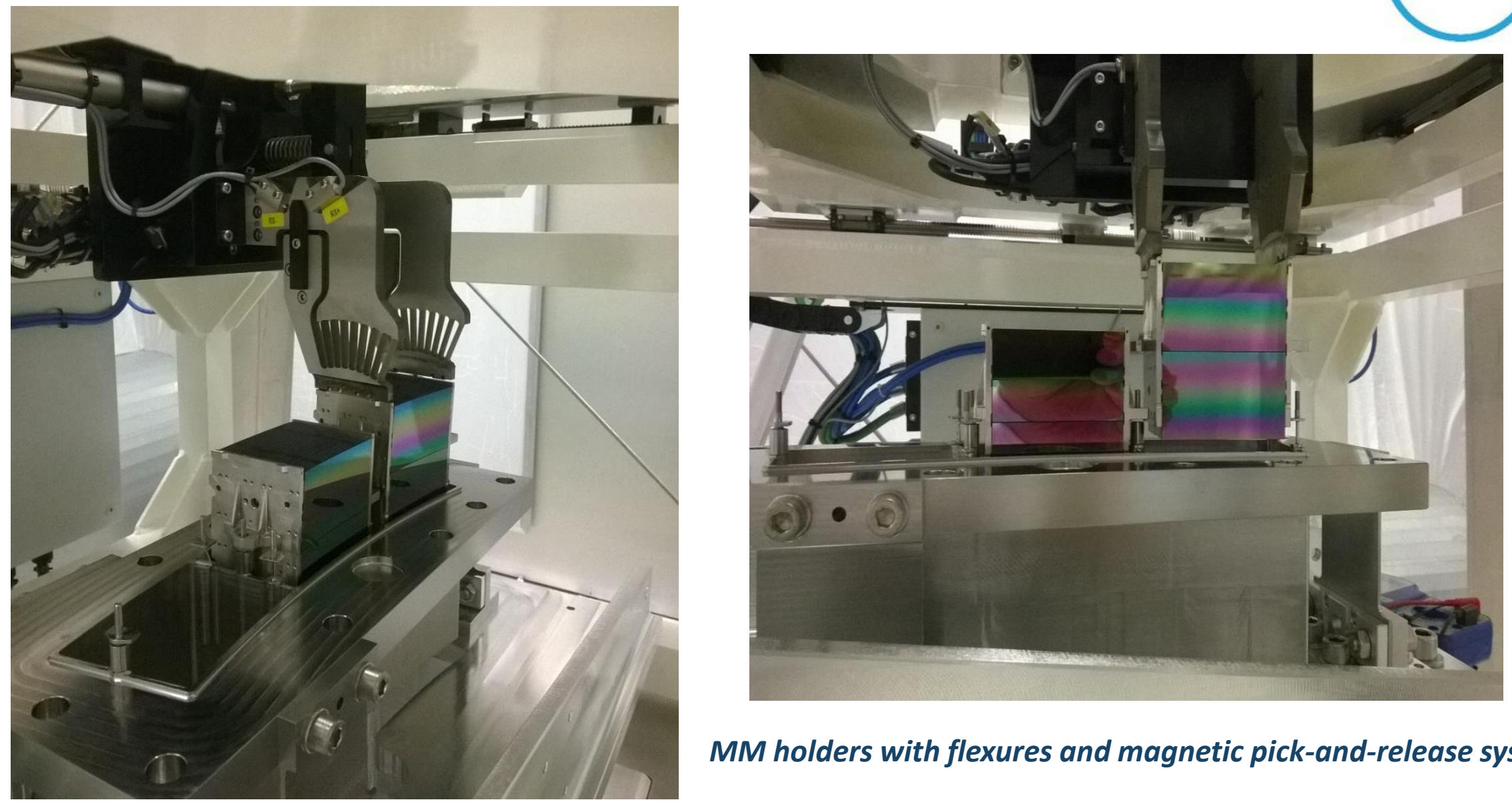

MM holders with flexures and magnetic pick-and-release system

$\mathrm{MM}$ holder have flexures and magnetic pick-and-release system for no distortion 


\section{Integration to Structure}

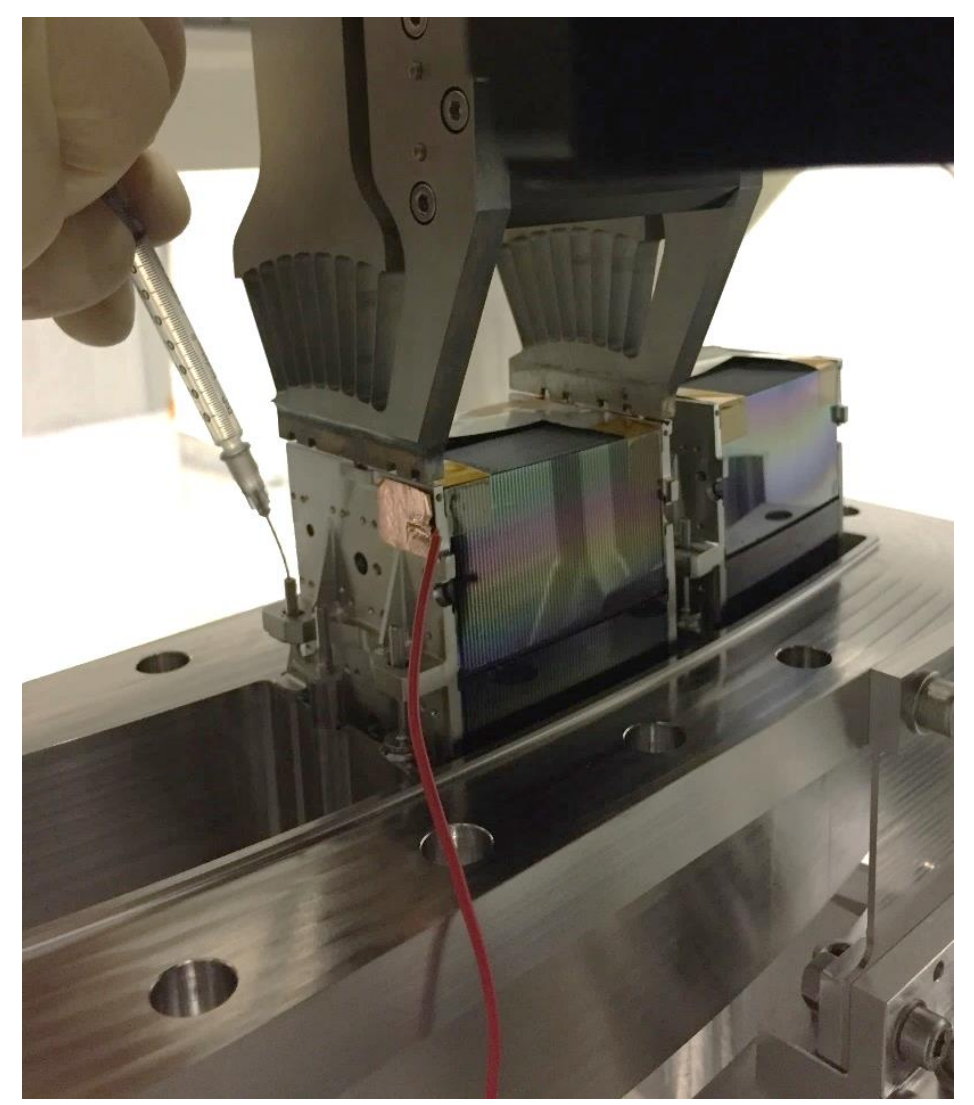

Injection of epoxy adhesive in the dowel-pin channel
Medía Lario

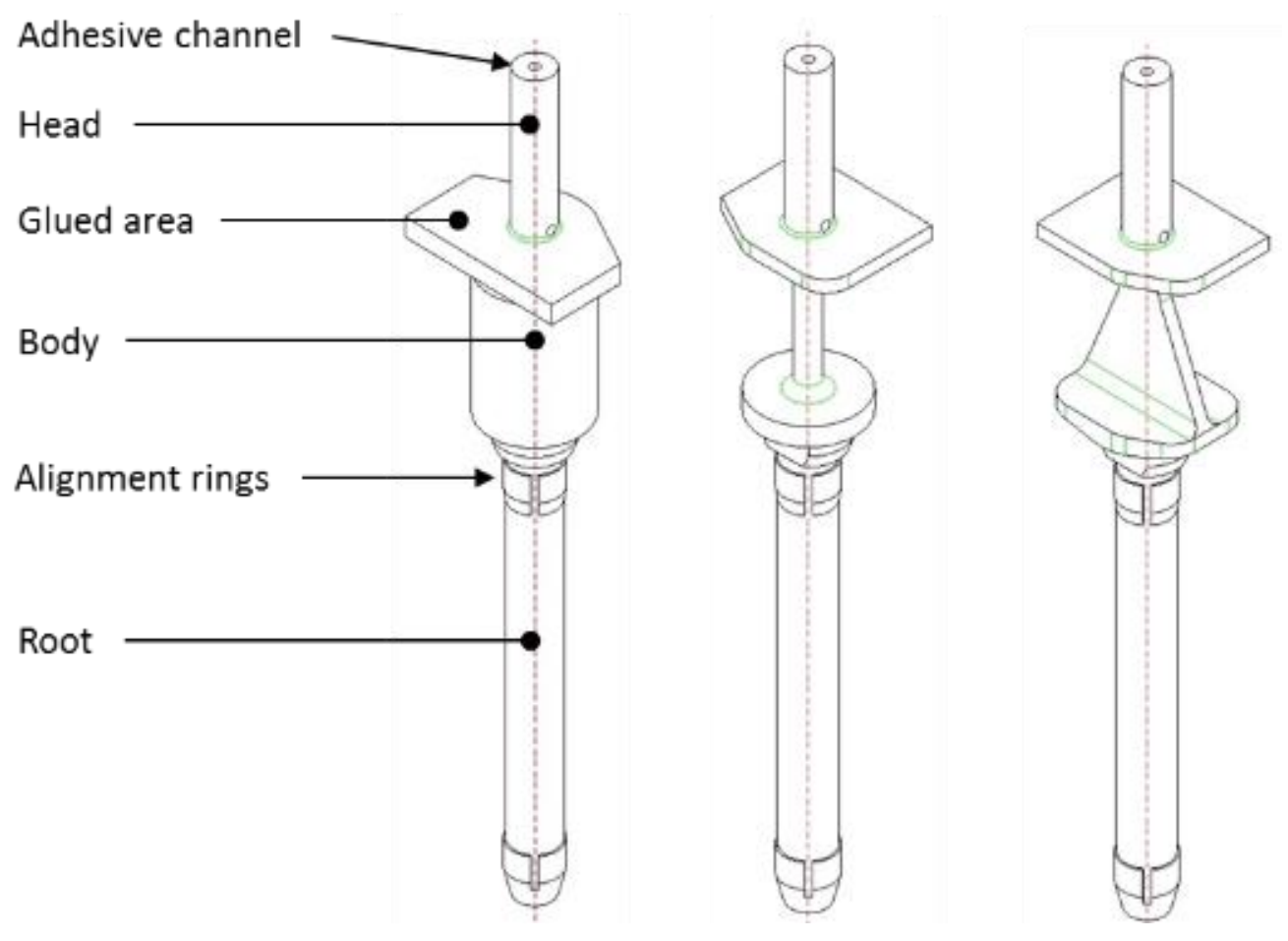

3 dowel pins to fix the MM to the structure

- Epoxy glue is injected in the dowel pins' channels while the MM is held in its aligned position

- Glue fills the $150 \mu \mathrm{m}$ gap between MM's bracket and dowel pin's plate by capillary action 


\section{Alignment Verification on Optical Bench}

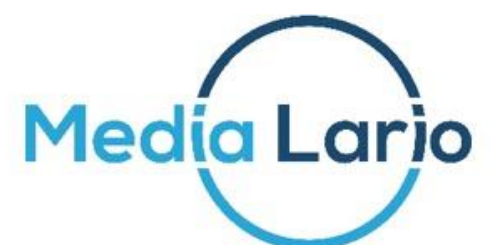

- Automated algorithm calculates centroid position

UV PSF images acquired at $12 \mathrm{~m}$ focal plane

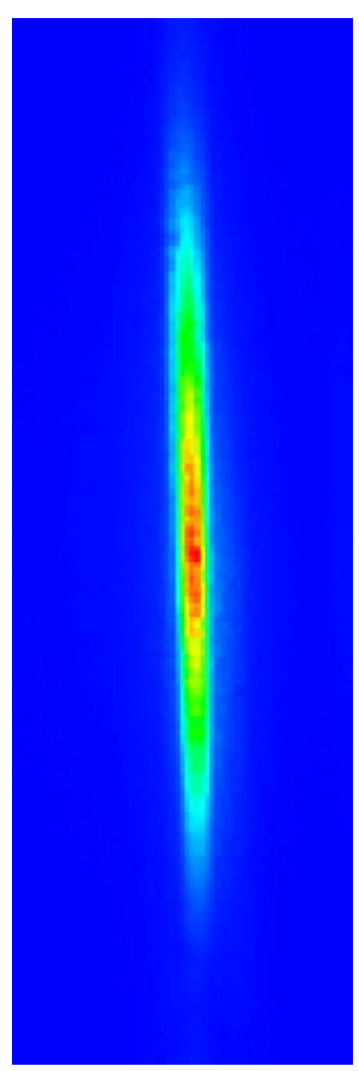

MM 0025

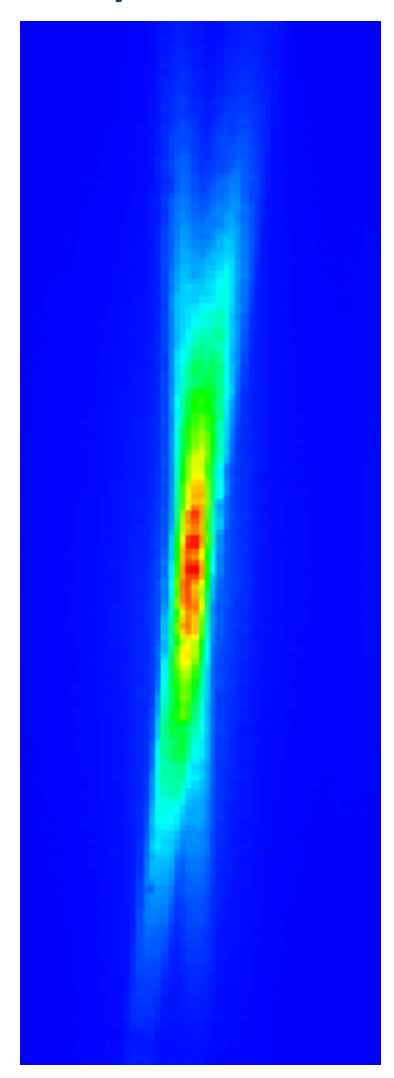

2-MM demo

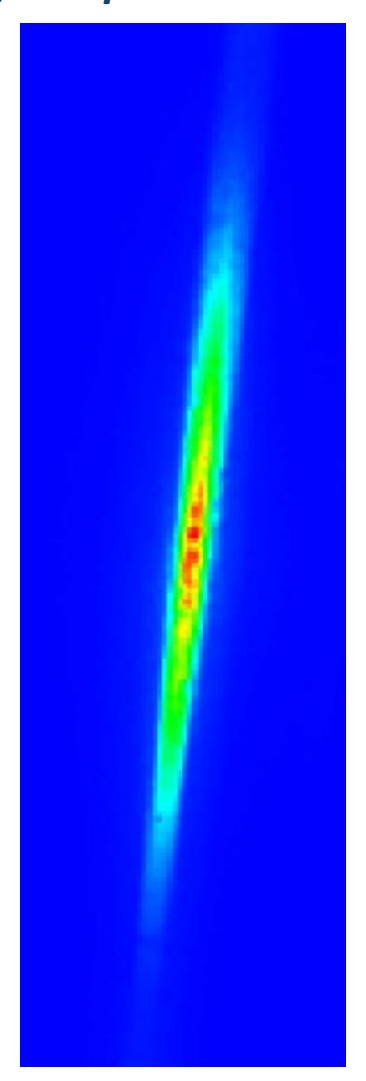

MM 0027

- 0.1 arcsec measured overlap of the two centroids

- Each MM took just few hours to align and bond to the structure

- The holder keeps MM in aligned position during the 12-hour curing process

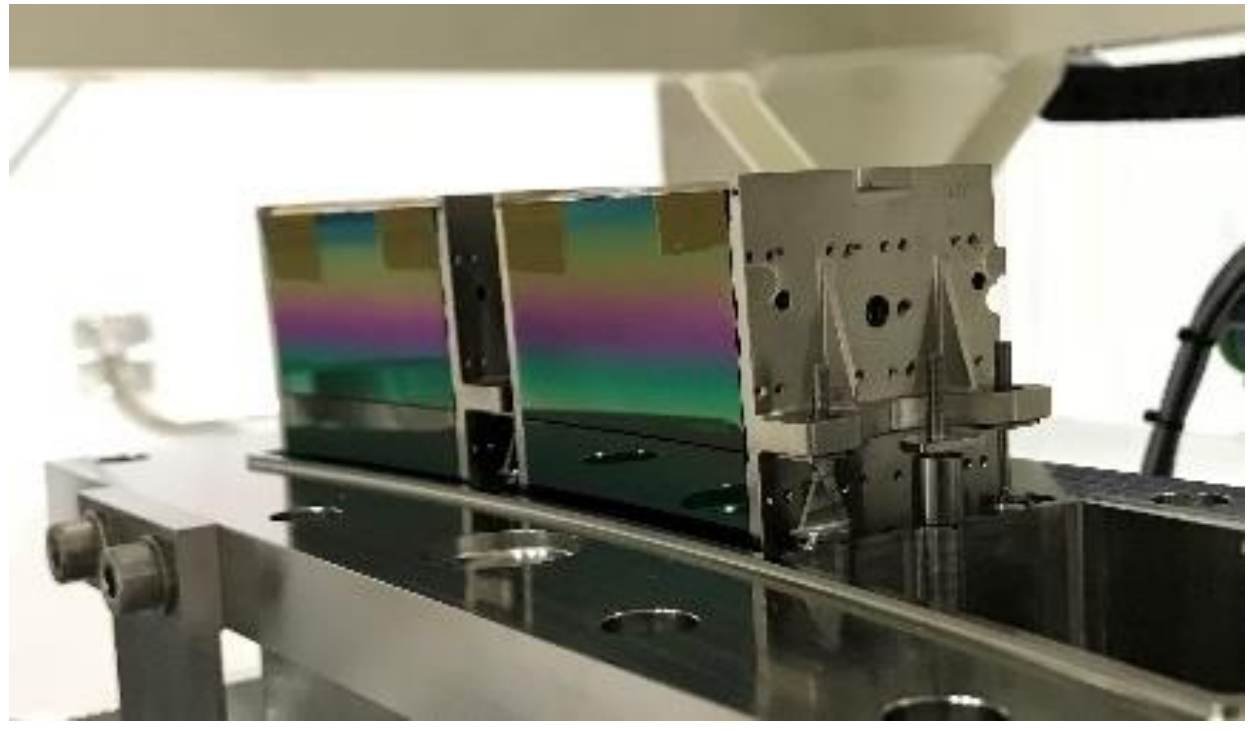

Demonstrator complete with 2 MM's aligned and integrated 


\section{X-ray Images at Panter}

$1.49 \mathrm{keV}$ measurements of Single MM's and full 2-MM Demonstrator

$X$-ray focal images at Panter

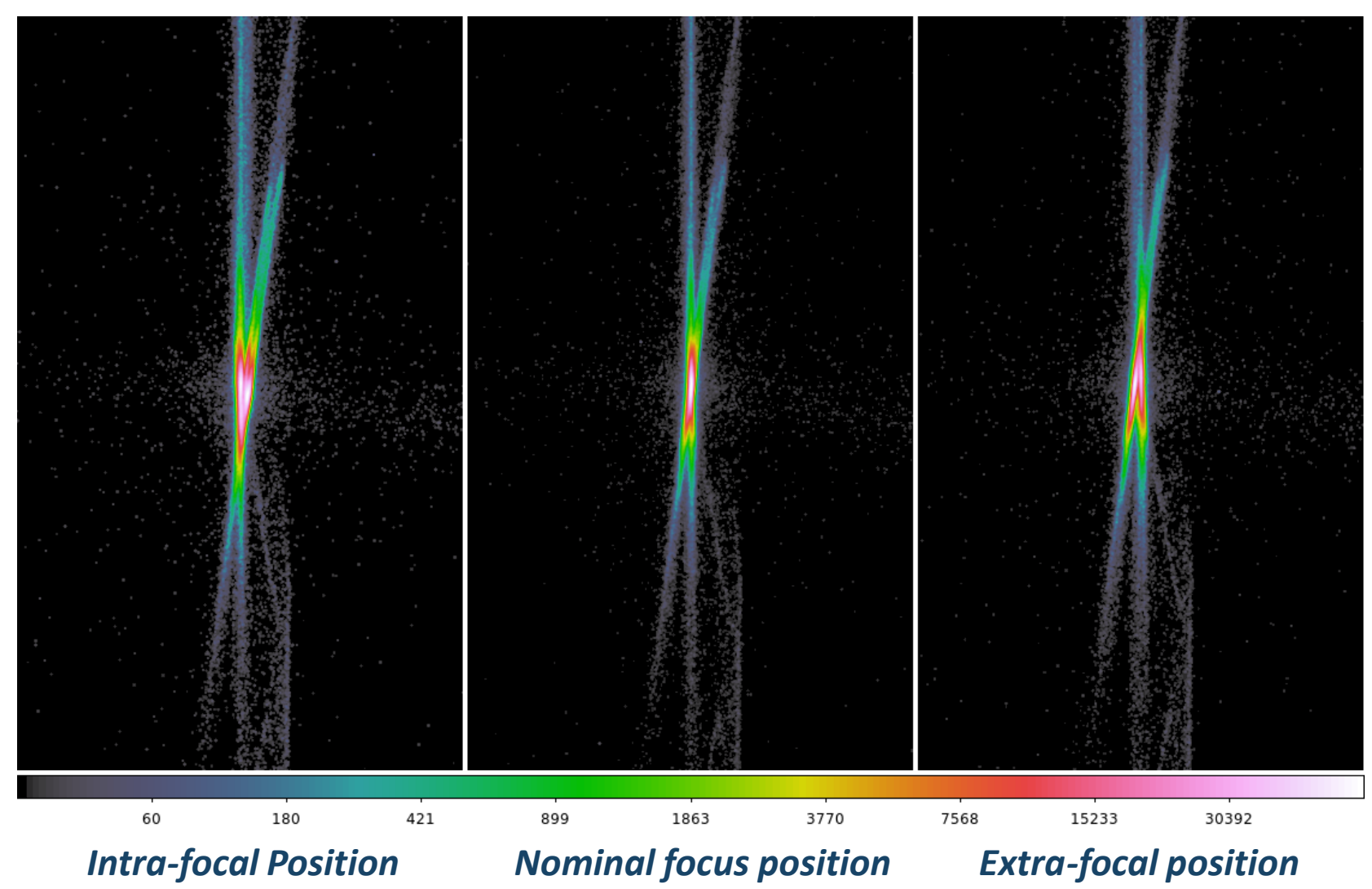

$218 \mathrm{~nm}$ UV focal image at Media Lario

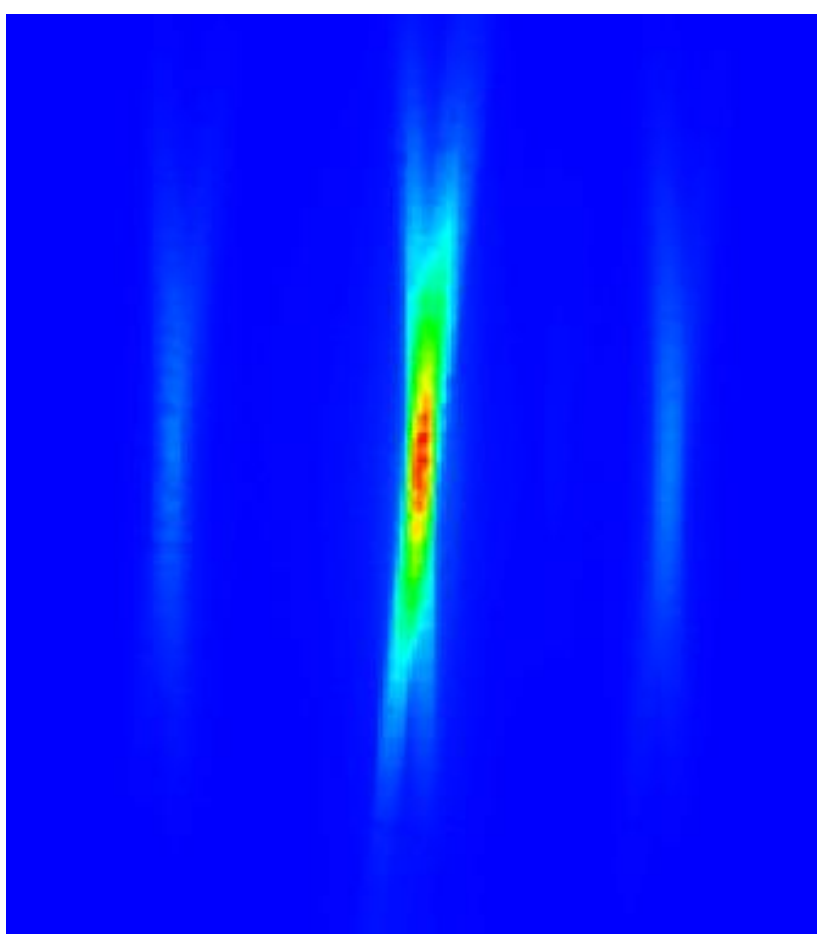

Nominal focal position

- X-ray images confirm overlapping of the two centroids 


\section{Alignment Results at Panter}

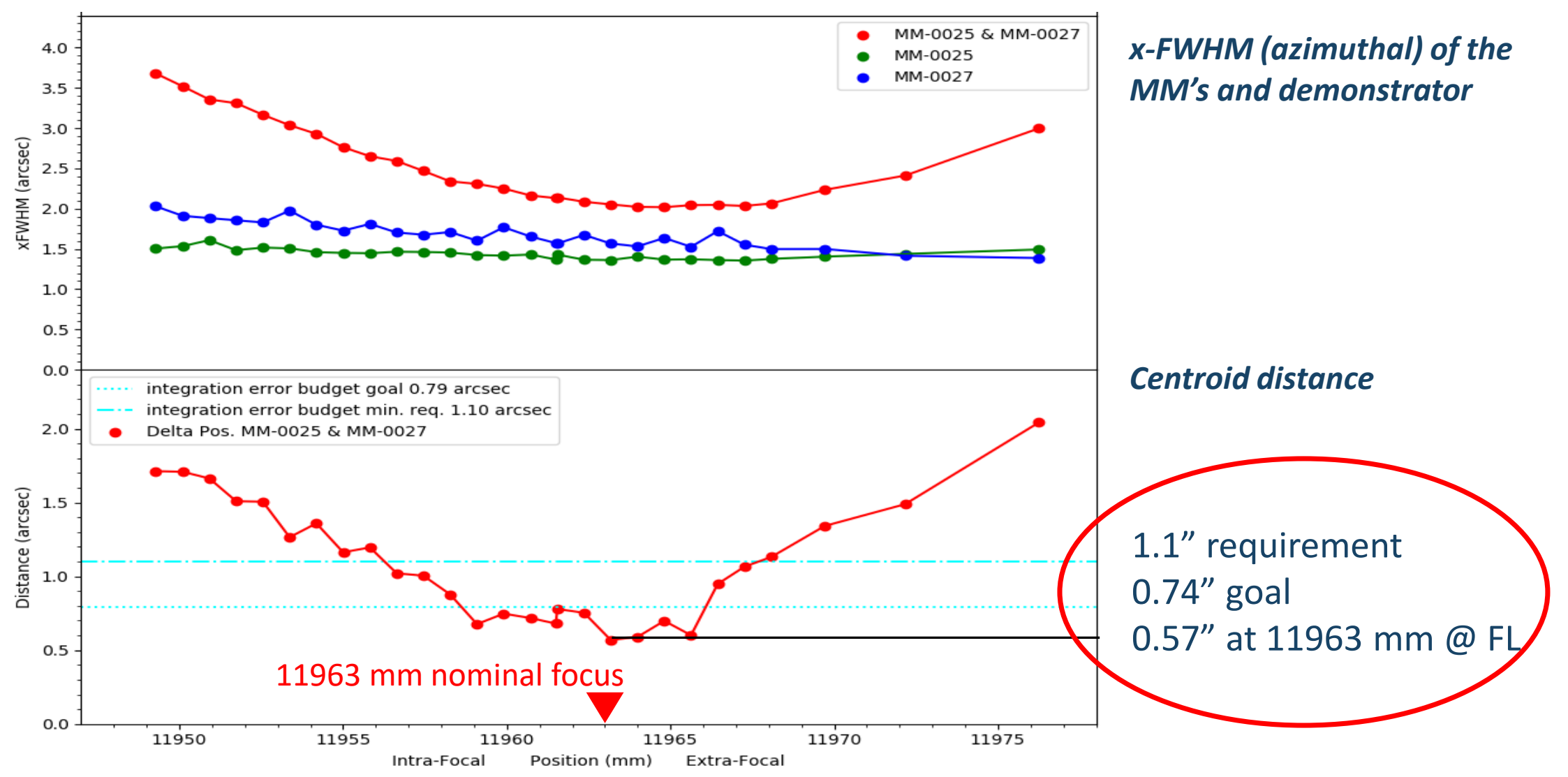

- Measurements confirmed 0.57 arcsec centroid distance against 1.1 arcsec requirement 


\section{Conclusions}

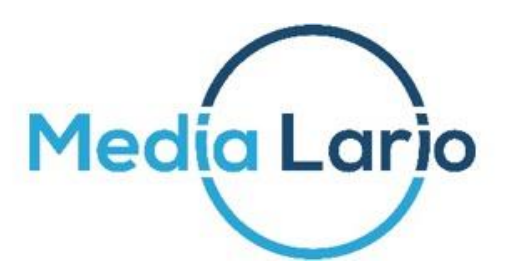

- The UV imaging at $218 \mathrm{~nm}$ integration process has been successfully implemented and verified at Media Lario using two Silicon Pore Optics mirror modules on an existing optical bench

- The distance between the centroids positions of the two mirror modules measured at X-ray wavelength at the PANTER test facility is 0.57 arcsec, well within the 0.74 arcsec goal derived from the overall telescope alignment and integration budget of 1 arcsec.

- No changes of the X-Ray performance after removal and re-integration of one MM have been measured.

- Scale up of the UV optical bench for the ATHENA flight telescope is feasible.

Met the ATHENA error budget for integration! 


\section{Alignment and Integration Process Characteristics}

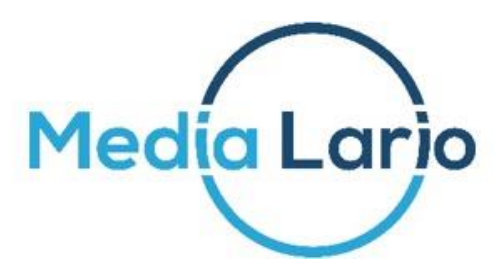

- Standard ISO 6 cleanroom, no vacuum infrastructure needed

- Integration of 2 MMs per day supporting 2-year total integration time

- Arbitrary integration sequence of the 700 mirror modules

- Option to remove, re-align or replace any mirror modules in any population scenario

- Real time verification of the mirror module alignment during bonding and curing

- Full-telescope illumination for overall performance monitoring

- Easy telescope realign procedure to allow intermediate X-ray tests 


\section{Highlight!}

Media Lario's technology for the alignment and integration of the ATHENA X-ray space telescope selected by the European Space Agency for further development.

Moreover, same technology selected by SAO, and proposed for integration of NASA ARCUS telescope 


\section{ATHENA Optical Alignment and Integration Tower}
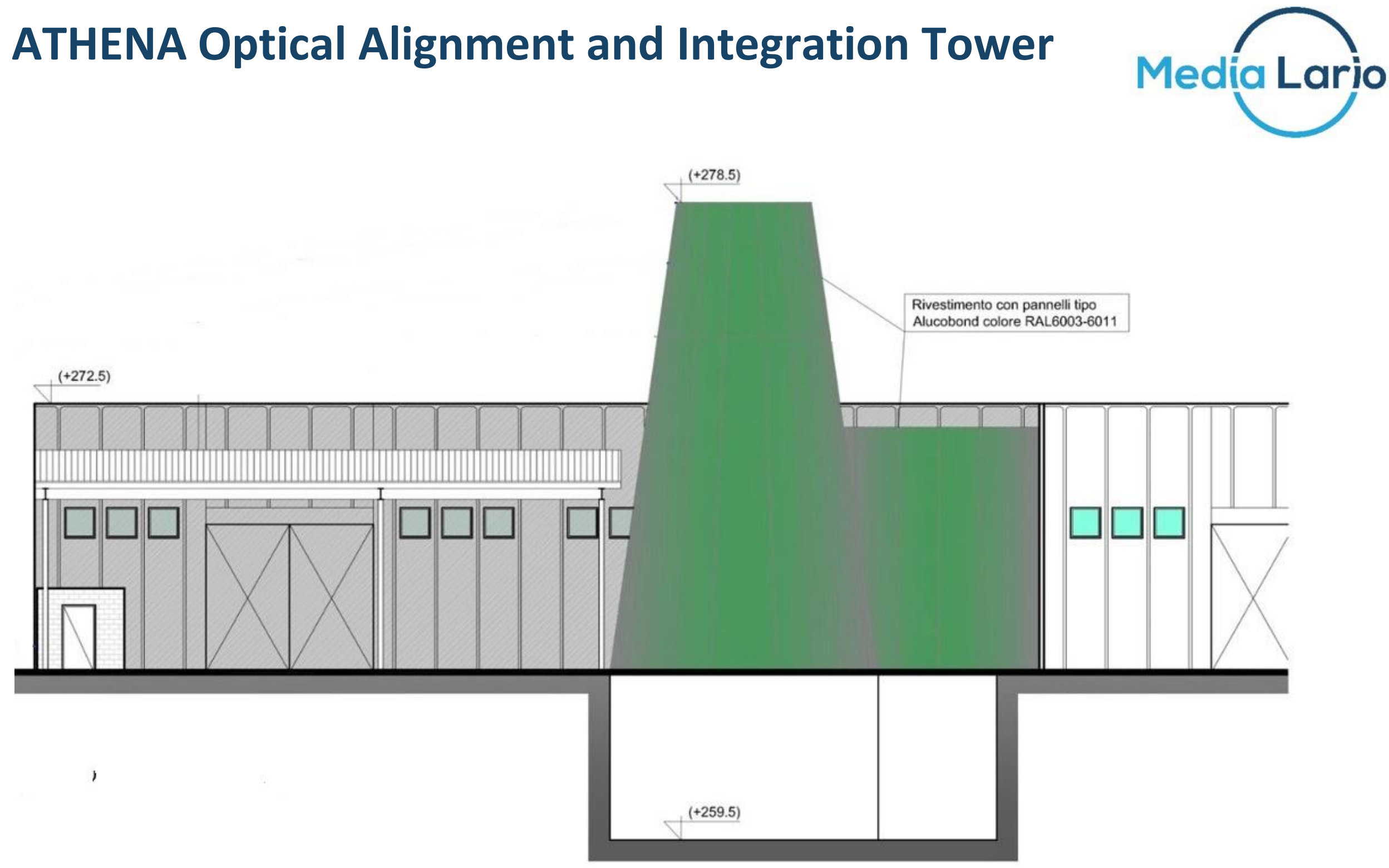

ATHENA integration will require a $\mathbf{2 0} \mathrm{m}$ alignment tower 


\section{ATHENA Optical Alignment and Integration Tower}
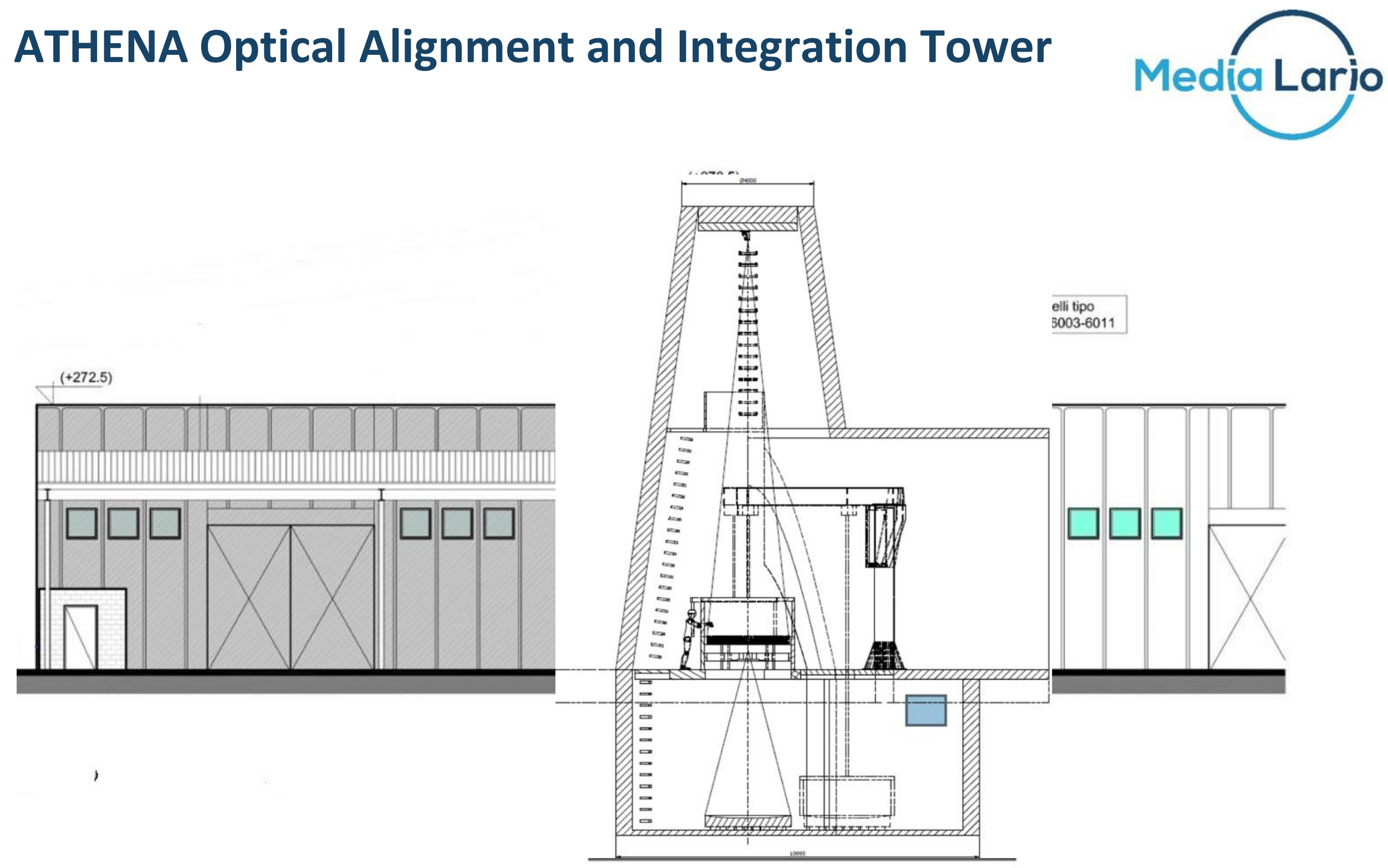

...a 2.6 m diameter collimator, a UV source, a CCD and 2 HADs 


\section{New Integration Facility Design}
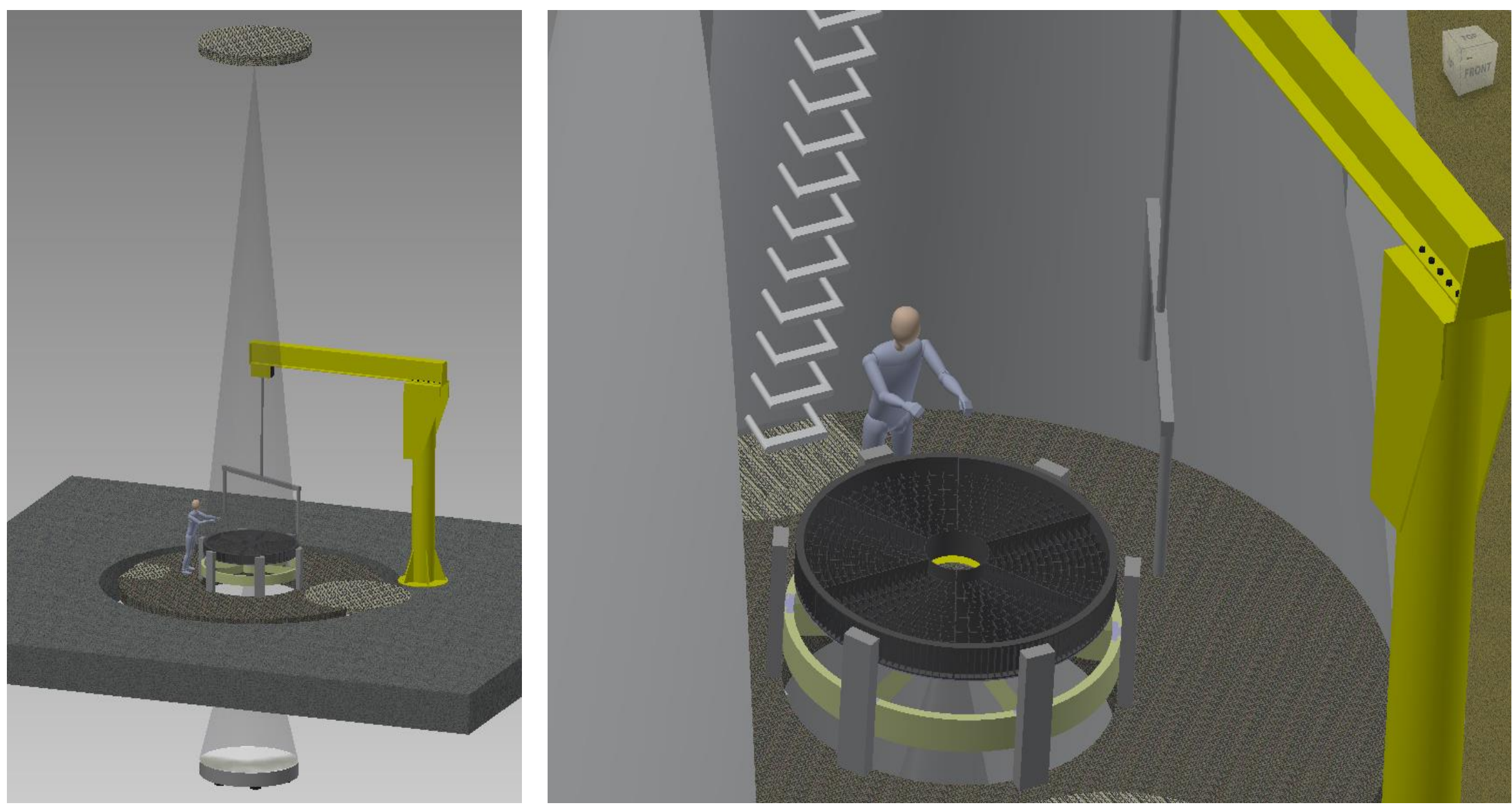
Thanks to Our Partners and to ESA

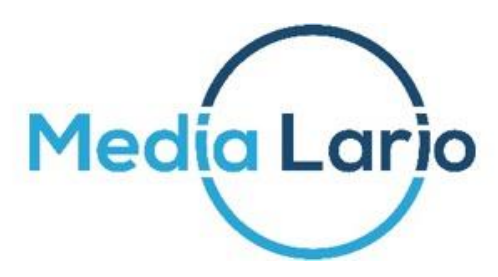

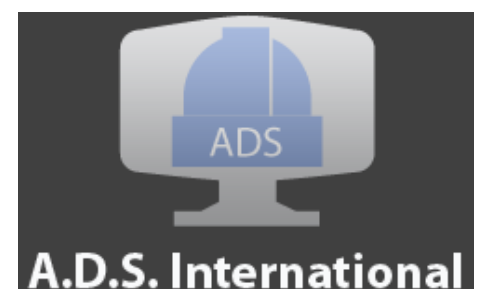

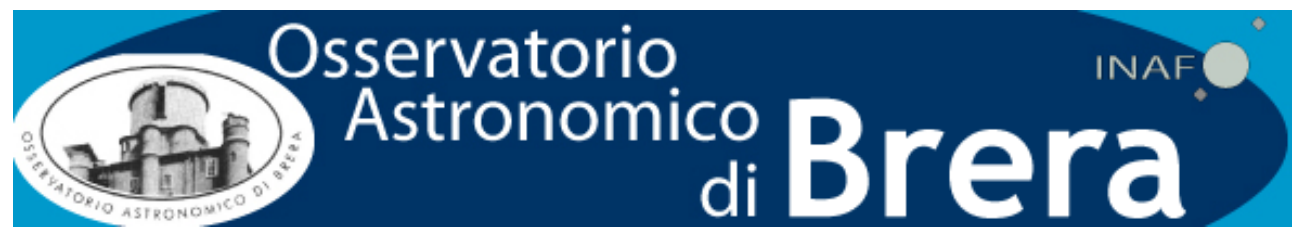

This project has been developed under ESA contract

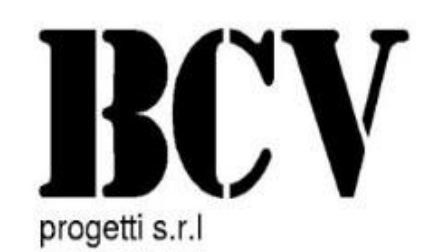

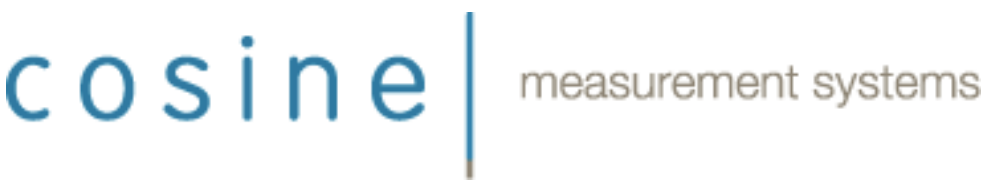

\section{ThalesAlenia \\ A Theies / Finmeconence combeny SPaCe}




\section{Thanks !}

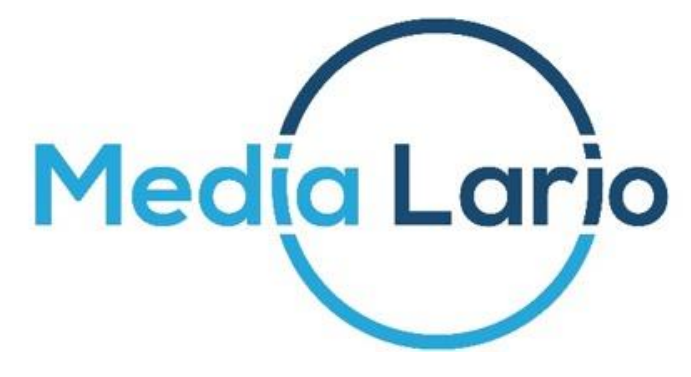

Media Lario s.r.I.

Via al Pascolo

23842 Bosisio Parini (LC) - Italy

Ph. +39.031.867111

info@medialario.com

www.medialario.com 